Article

\title{
i-Sustainability Plus Theory as an Innovative Path towards Sustainable World Founded on Blue-Green Ubiquitous Cities (Case Studies: Denmark and South Korea)
}

\author{
Hamid Doost Mohammadian $1, *\left(\mathbb{D}\right.$ and Fatemeh Rezaie ${ }^{2}$ \\ 1 Management Department, University of Applied Sciences (FHM), 33602 Bielefeld, Germany \\ 2 Management Department, Industrial Management Institute, Tehran, Iran; baharrezaie70@gmail.com \\ * Correspondence: Doost@fh-mittlestand.de; Tel.: +49-1-762-0826-905
}

Received: 2 December 2019; Accepted: 24 March 2020; Published: 30 March 2020

\begin{abstract}
Nowadays, the new concept of urban living is required as a path to struggle with urbanization challenges in order to maintain the world and make cities better settings for living through creating high quality of life and liveability. To achieve such areas, developing sustainability, urban planning based on Information Technology, Information Communication Technology infrastructure, and innovative management play important roles. So, authors try to find out new concepts of urban life concerned with these indicators through sustainability, innovation, ubiquitous, and smartness to create a sustainable and modern world through smart cities. Based on authors' researches, Blue-Green infrastructure based on environmentally friendly, green strategies, sustainable water management, and ubiquitous services focusing on digitalization and high technologies are required to make a modern world. Fundamentally, innovation management in technology, business and marketing has important roles in designing such areas by keeping up with growing demands and low resources of energies. In this research, i-Sustainability Plus is introduced as a theory to create Blue-Green Ubiquitous cities as modern sustainable and liveable urban areas. Such areas could make the world a better place for living through sustainable development and improving quality of human life.
\end{abstract}

Keywords: sustainability; ubiquitous; smartness; innovation; blue-green infrastructure; sustainable innovative world; quality of life; livability

\section{Introduction}

Nowadays, the world confronts global challenges including poverty, slum, economic problems, environmental challenges, climate change, social instability, insecurity, and health disease. Rapid and unplanned urbanization, high emissions of greenhouse gases made by industry, transportation, agriculture and humans' activities, high demands of humans, and destruction of the environment by mankind are the main reasons for these challenges. Global challenges are significant threats not only for the world and environment, but also for human beings. These challenges and risks could make quality of life and livability worsen and destroy the future of living in the plant. So, it is vital to struggle with them to preserve the world and humanities. Generally, sustainability and sustainable development are introduced as keys to deal with them. Further, features of the fourth wave high technologies such as Information Technology, Information Communication Technology, cloud computing like Internet of Things, Internet of Business, Internet of Energy, Internet of Manufacturing and digitalization could be used as techniques to deal with global challenges. In other words, high technologies and digitalization have changed humans' lives through inventing new techniques such as renewable energies, innovative management, and ubiquitous and smart services like hybrid vehicles. 
So, they could struggle with global problems through achieving sustainable development. Therefore, sustainability, high technologies and digitalization could be tools to create new urban areas with high quality of livability, and less global challenges especially environmental problems and greenhouse gas emissions through comprehensive sustainable urban planning and sustainability. In this research, Blue-Green Ubiquitous cities are introduced as a key to struggle with global challenges. Such cities are based on green strategies, sustainable water management and environmental friendliness. Ubiquitous and smart services, innovation, and smart citizens have important roles in creating Blue-Green Cities. In this research, i-sustainability plus is introduced as the theory invented through ubiquitous and smart services, innovation and sustainability in order to create modern cities like Blue-Green ones. The main aim of the study is to create a practical model to suggest how Blue-Green Ubiquitous cities could be used as a tool to design modern urban settings in order to achieve sustainable development and sustainable areas with high livability and quality of life through struggling with global challenges. In addition, three sub-goals are also the main aims of this research. The first sub-goal is to indicate how Blue-Green Ubiquitous cities could be developed. The second sub-goal is to find out how sustainability can improve livability and quality of human life, and the last aim of the study is to find out how would modern urban settings struggle with global challenges.

\section{Background}

\subsection{Global Challenges}

The world confronts significant challenges that threaten the future of the World as well as livability and quality of human life in the present. So, it is vital that all the regions and countries participate to deal with these problems. Climate change, aging, AIDS, health's problems, children, decolonization, democracy, poverty, food, gender equality, human rights, justice, environmental problems, energy, water challenges, and urbanization problems are nominated as the most important phenomena by United Nations (UN). Besides the UN, World Economic Forum (WEF) has proposed global risks such as climate-change, weapons of mass-destruction, water crises, largescale involuntary migration, and severe energy price shocks in 2016. Although these risks and opportunities vary from region and country, all countries have to use strategies to deal with them and maintain the world (WEF). Fundamentally, these risks could be changed to opportunities through utilizing policies to achieve sustainable development.

Economic, social and environmental changes are the main reason for global risks. These changes make global challenges nominated by UN and WEF. Fundamentally, sustainable development and sustainable solutions are the best keys to struggle with these challenges in order to maintain the world and improve livability [1].

\subsection{Sustainability and Sustainable Development}

For the first time in 1713, Carlowitz presented the new idea of sustainability. Then in the first half of the 18th century, the idea of sustainable revenue was published in Denmark, Norway, Russia, and France, but it was not until the 1970s that the idea of sustainability was officially stated [2,3]. In 1980, the idea of sustainable development was declared for the first time in the World Conservation Strategy drafted by the United Nations Environment Program (UNEP) and the International Union for the Conservation of Nature (IUCN). Then in 1995, Agenda 21 was presented, concerned with access to land, security of land tenure, tenants' rights, liberalized credit policies, and low-cost building material programs for "sustainable" urban living for the homeless and for the urban poor [4]. Fundamentally, sustainable development occurred in an effort to improve human well-being in the long term through management of the human environmental system [2,5]. Environment, economic, and social well-being are three traditional pillars of sustainability required to gain sustainable development. There must be an equilibrium to achieve sustainability $[4,6]$. 
Based on the authors' point of view, a new definition for sustainability is required to deal with urbanization challenges and sustainable development. A new concept of sustainability composing of seven pillars is proposed by the authors, instead of the three pillars that make up the traditional notion of sustainability-environmental, economic, and social sustainability. Environmental, economic, social, cultural, educational, political, and technical sustainability are the main components of high sustainability. It is required that these seven pillars are developed fairly equally. In particular, two points are important for high sustainability theory introduced by authors: The first point is that seven pillars including education, culture, social, technique, politic, economic, and environment are vital to gain high sustainability. The second point is that these seven pillars of sustainability must develop almost equally [7]. The below Figure 1 shows these two points:
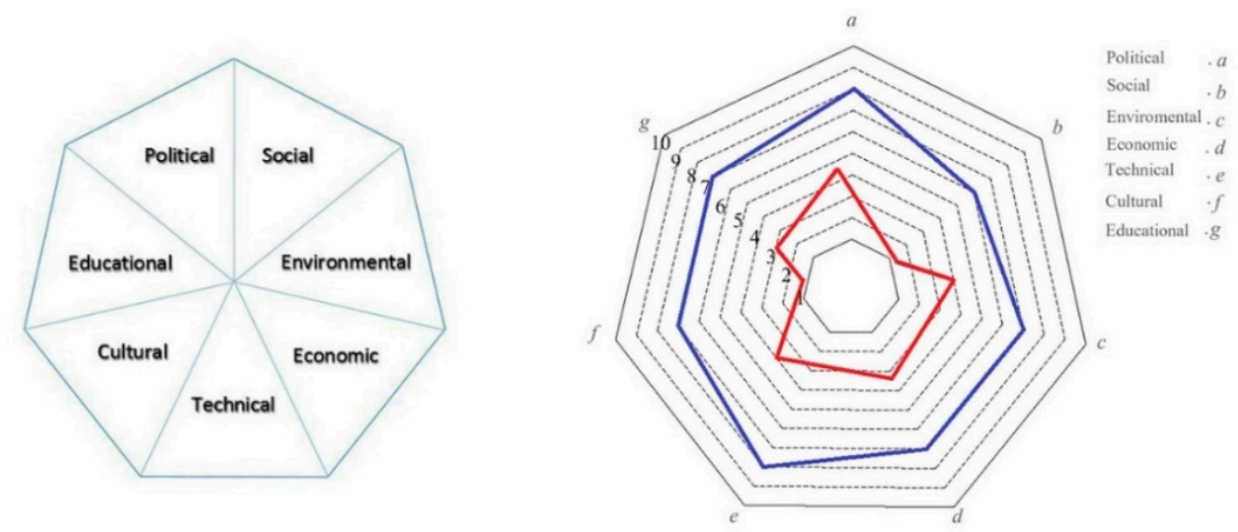

Figure 1. 7 PS Model [7-9].

\subsection{Blue-Green City}

Green cities based on green policies and being environmentally friendly are not sufficient enough to tackle global challenges as well as to create livable urban areas. Therefore, new solutions are needed to improve the livability of urban areas for the present generation and preserve the world for upcoming generations. Blue-Green infrastructure and cities are realized as a good solution to tackle global challenges as well as create modern livable urban areas.

Blue-Green cities are based not only on green policies and being environmentally friendly, but also on sustainable water management. The main goals of these cities are to mitigate flooding, reduce water sacristy, enhance ecosystems, design a platform for stakeholder engagement, improve sustainable developing, and improve the quality of living [10].

To gain a Blue-Green city, Blue-Green infrastructure concerned with tormwater management, water security, flood management, tree health, and recreational needs is required. To explore synergistic opportunities for integrated greening and water management outcomes and to create a framework for collaboration between council departments and key industry and community groups to deliver a new blue-print for cities and towns are the main aims of Blue-Green infrastructure [11]. Generally, this infrastructure is related to two indicators: landscape planning concerned with open space strategy, urban forest strategy, biodiversity and environmental policy; and water planning including sustainable water use planning, integrated water management strategies, flood studies, and a stormwater management plan. Blue-Green infrastructure is required to achieve Blue-Green cities [12].

Fundamentally, Blue-Green infrastructure including principles of healthy urban living, Design principles multifunctional green infrastructure, key factors to gain healthy urban water, and strategies to maintain nature and the environment could create healthy urban living based on a healthy urban environment and healthy lifestyle in order to make high livability and quality of life for citizens $[13,14]$. 


\subsection{Digitalization and Smart Life}

Digitalization is the integration of digital technologies into everyday life that can be digitalized. Digitalization is a tool to achieve solutions and strategies towards sustainable development [15].

From 1970s, technologies, IT, information and communication technologies, and transport infrastructures have influenced humans' lives. In other words, the growing opportunities in improving peoples' quality of lives and livability have been achieved by new technologies [16]. Generally, urbanization challenges like work, education, well-being, economic situation and social life, environmental problems, climate change, carbon dioxide, greenhouse gases emissions, and waste disposal with consequences on health conditions can be solved through high technologies [17].

Smart city is a combination of information city, digital city and sustainable city. Generally, smart economy, smart mobility, smart environment, smart people, smart living, and smart governance form smart cities [18]. Smart cities make innovation by planning, management and operation of their infrastructures and resources and they have to cope with the future demands of their citizens. In smart cities, the usage of new information and communication technologies (ICT) facilitates smart administration and good governance using tools such as e-governance and e-democracy [19]. Fundamentally, the benefits of sustainable and smart cities are:

- Enhance quality of life

- Improve economic situation and create better employment opportunities

- Improve well-being of its citizens by ensuring access to social and community services

- Establish an environmentally responsible and sustainable approach to development

- Ensure efficient service delivery of basic services and infrastructure such as public transportation, water supply and drainage, telecommunication, and other utilities

- Struggling with climate change and environmental issues

- Provide regulatory and governance mechanism ensuring equitable policies [18].

\subsection{Ubiquitous City}

U-City is a 21st century futurist city that provides a service such as a one-stop administration service, automatic traffic, crime prevention, fire prevention system, and home-networking of residential places, which fused high-tech infrastructure and ubiquitous information services into the urban area $[19,20]$. U-City is introduced as "a city in which ubiquitous based services are offered at any time, in any place at urban space by realizing high-tech IT, construction, traffic application technologies to enhance urban life quality and city competitiveness" [21]. In a U-city, each citizen can use any services anywhere and anytime via ICT devices. Furthermore, U-city could develop environmental sustainability, sustainable and smart city through making computing widely available to the urban elements such as people, building, infrastructure, and open spaces [19]. U-city is based on U-life and U-services such as smart building, smart and ubiquitous management services, smart city, sustainable environment services, digital public portal, smart and sustainable transportation services, climate prevention services, and ubiquitous concept. U-City is the next-generation of information-based cities that make every function of the city including urban life, improvement of quality of life, security guaranteeing by systematic city management, improvement of citizen welfare, and new industry creation, be improved and promoted through utilizing technologies systems as well as innovation [21].

\subsection{Innovation}

Innovation is the embodiment, combination, or synthesis of knowledge in original; relevant; valued; and new products, processes, or services. Fundamentally, innovation has three levels: invention, implementation, and end product. The challenge is to cultivate and leverage innovation capabilities that continuously deliver innovations. All innovation begins with creative ideas. Innovation is defined as the successful implementation of creative ideas within an organization [22,23]. Innovation is not just 
about new products and technology. It is vital to improve business and make an economic situation profitable [24].

The below Figure 2 presents the most famous types of innovation models:

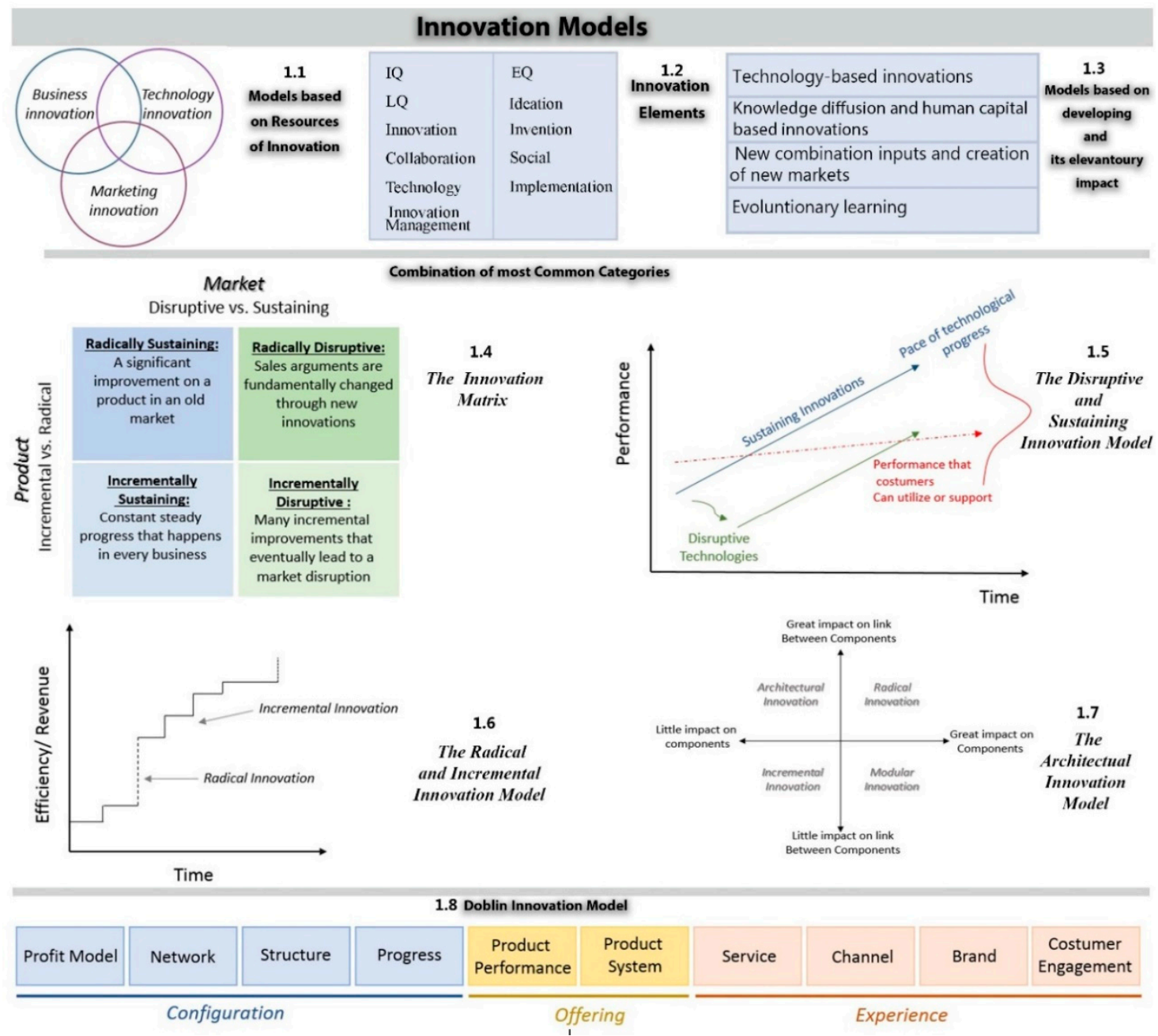

Figure 2. Innovation models (Adopted from References [8,25-28]).

\section{Methodology}

To address the aims of this research, some questions should be answered:

1. How could i-Sustainability Plus Theory create a Sustainable World?

2. How would Blue-Green Cities be created through i-Sustainability Plus?

3. How would Blue-Green Ubiquitous cities deal with global challenges to achieve sustainable development?

4. What indicators and strategies are required to design Blue-Green infrastructure?

5. What is the role of ubiquitous concept in creating sustainable and livable urban areas based on a Blue-Green city?

In order to answer the research questions and achieve the aims of this study, it is important to pursue a sound methodology. In this paper, three stages were developed to implement the study:

Stage 1: The development of a research methodology.

This stage was developed on the basis of the literature review in the area concerned with objectives of this research. The authors have thoroughly investigated papers published in the context of sustainability, sustainable development, smartness, digitalization, smart city, ubiquitous city, 
Blue-Green infrastructure and city, innovation, and innovation models. In addition, global challenges that are significant threats for the quality of life and future of the world and role of sustainable urban areas in dealing with these challenges were explored.

Stage 2: The development of the research tool.

The research tool was developed on the basis of the relevant literature, exploring case studies, knowledge, and personal experience.

The purpose of surveys and case studies was to indicate policies, strategies, and solutions utilized by case studies in order to find out the roles of innovation, sustainable project management, and sustainable development in facing urbanization challenges.

Stage 3: Gathering the study results and analyzing.

Based on literature reviews, surveys, case studies and analyses, some results were obtained, and these results were analyzed and discussed by the authors.

\section{Case Studies}

In this section, two countries concerned with Blue-Green strategies, smartness and ubiquitous are probed in order to find out solutions and innovative responses to gain sustainable development, high livability and quality of life.

\subsection{Denmark/Bornholm}

Denmark is one of the most sustainable countries in the world. It is nominated as the green capital, green country and sustainable capital. Sustainability is estimated by the scale of economy, economic situation, development, peace, and stability; Denmark ticks all of these boxes.

OECD introduces Denmark as the most energy secure and sustainable country. The country has reduced its dependence on foreign sources of energy to zero and become self-sufficient in its own energy production and use, offering important lessons for other nations around the world [12].

Fundamentally, green power, sustainable mobility, sustainable waste management, and green life make the environment sustainable. Denmark is not only environmentally sustainable but also socially and economically. Sustainable economics exists in Denmark by proper economic strategies such as growth concept, stable banking, finance sector, business strategies, and innovative financial risk management policies. For instance, Bornholm is a Danish island that is one of the richest regions of the world. Bornholm is a home to generate novel energy market mechanisms to regulate energy networks with a high prevalence of renewables (such as wind turbines and photovoltaics) and this reason makes it so rich. Bornholm is a good example of proper business strategy used by Denmark.

In particular, Government plays important roles in creating such urban areas. The Danish Government has established strategies to improve sustainable and smart infrastructure and life in the country. All these strategies are aligned with being environmentally friendly and Blue-Green concept. The most important ones are:

- Independency of fossil fuels through using clean and inclusive energies such as biofuels and etc.

- Transportation based on clean and renewable energy

- Bike as main transportation system

- Improving public transportation

- Infrastructure based on smartness

- High standards

- Smart architecture and construction to reduce consumption of energy

- Enhancing cultural norms and education systems

- High standards of living through facilities such as proper insurance, high education, employment etc.

- New process and technologies in industry, transport and others in order to make efficiency and productivity higher with lower consumption of raw material and energy 
- Making new opportunities through risks by innovation, high technologies and digitalization

Besides government policies and strategies, all Danish mobility organizations use smart and sustainable policies to be aligned with not only the sustainability of the country, but also the world. Maersk is a qualified example. Maersk is a Danish business conglomerate with activities in the transport, logistics and energy sectors, and it is the largest shipping company. It follows strategies to gain Blue-Green, smart and sustainable mobility such as reducing $\mathrm{CO}_{2}$ emissions by $40 \%$, plying bio fuels to owner its fleet, setting the main goal of being carbon neutral in 2015 and using special category management including: stakeholder management, category strategy and sourcing, supplier relationship management, proactive category management and renegotiating agreements, and special risk management in different categories. All these policies make sustainable and smart water transport aligned with being environmentally friendly.

Fundamentally, policies and strategies utilized by governments and organization related to mobility make Denmark a green and sustainable state aligned with the Blue-Green idea. In addition, sustainability makes for a high quality of livability and high quality of life in Denmark.

\subsection{South Korea/Seoul}

South Korea is a pioneer of designing and creating a U-city. It strives to use such cities as solutions to deal with challenges confronted by, such as rapid urbanization, supplying citizens' needs, environmental challenges, contamination, etc.

U-City emerged in the political arena first in 2004 and the second step toward the realization of ubiquitous society is the enactment of the 'Act on Ubiquitous City Construction', which occurred in 2008 in Korea. Physical, spatial urban development with ubiquitous technologies are combined in a U-city. So, the limitation on physical distance and time could be overcome and a new urban model for a sustainable, intelligent city will be developed [29].

For the first time in 2007, U-Eco City based on high technologies and ecology was developed in South Korea. The project lasted from 2008 to 2013. The U-Eco City is defined as a "sustainable future green city that produces an innovative city related to the integration of ubiquitous and ecology technology into the city space." The main dimensions of this project are:

- Eco city planning, design, and evaluation based on u-technology

- Construction technology of the u-water circulation system

- Construction technology based on low-energy and recycling

- Eco city construction fusion technology based on u-technology

The main goal of this project is to design a future-oriented, sustainable city where city management technologies based on ubiquitous infrastructure and the ecological system are combined and would create a comfortable urban environment for urban citizens [29].

Seoul as the capital of South Korea and the largest metropolis with over 10 million citizens has been one of the controversial cities with global challenges, and U-city design is declared as a solution for this city.

After 1953, Seoul developed quickly, and it caused environmental problems. Since the 1990s, urbanization has grown more rapidly and this has caused a lot of problems such as air and water pollution, environmental challenges, etc. These challenges not only influence citizens' lives and livability, but also make citizens dissatisfied. So, Seoul had to struggle with these problems to develop sustainability in order to improve quality of life. Ubiquitous city and smart city are declared as the best solutions for Seoul to struggle with its problems. In particular, it is needed to struggle with urbanization challenges as well as being kept up with growing inhabitants' demands. Therefore, besides sustainability, ubiquitous concepts based on digitalization, high technologies and smartness are required as solutions. Generally, ubiquitous services and innovative solutions based on smartness have important roles in creating new urban settings in Seoul. It means that these services could develop sustainability and be aligned with growing urbanization demands. 
Fundamentally, three indicators are realized to use in Seoul as solutions:

- ICT infrastructure: ICT infrastructure is vital to achieve U-city services. Efforts to develop ICT infrastructure must anticipate future service demands, rather than respond only to those most apparent.

- Integrated City-Management Framework: Management framework is vital to gain U-services in cities. The many integrated subsystems, meta-systems and individual building-block systems of U-city could work through standards.

- Smart Users: Although ICT is used as a tool in U-cities, citizens who could use smart tech to interact with smart services are vital to achieve U-life in cities.

Generally, three major programs are used as a smart strategy to gain ubiquitous trades in Seoul. The first is an open data approach, which makes the sharing of government data the default rather than the exception. Active interactions with citizens via e-platforms, including almost daily city-wide voting on municipal issues via a smartphone app, is the second strategy. The third is the systematic mining of big data to improve municipal services [29,30].

Fundamentally, almost every aspect of public life in Seoul is guided by technology, from its integrated public transport system to the government's emergency warning system. So, Seoul is a ubiquitous city. Ubiquitous services not only struggle with Seoul challenges, but also develop sustainability and improve citizens' lives. In other words, ubiquitous services make Seoul a livable and sustainable urban setting as well as reduce global challenges that it is confronted with. Therefore, U-services and U-city are a solution for cities such as Seoul that are faced with global challenges and rapid urbanization towards creating sustainable and livable urban areas.

\section{Result}

Based on research and analyses of articles [10,12,13,29-40]; the following was concluded:

According to UN reports, the World confronts global challenges including environmental concerns, climate change, poverty, slum, health challenges, insecurity, inequity (income, discrimination), economic problems, etc. that threaten not only sustainability, but also the future of the world and humanities. It is time to deal with these challenges in order to reduce and control them towards achieving sustainable development. Fundamentally, sustainable development is the key to maintain the world for upcoming generations and improve the quality of human life. As rapid and unplanned urbanization is one of the main reasons for global challenges, new concepts for urban settings are required to be able to control these challenges and develop sustainability. Based on the authors' view, Blue-Green cities based on sustainability strategies, high technologies and innovation are tools to make the world a better place for living.

Different tools, solutions, techniques and strategies are required to achieve such cities. In particular, high technologies, innovation, and smart citizens are needed as well as Blue-Green strategies. Although Blue-Green strategies based on environmentally friendly policies and water management are techniques to develop sustainability; innovation, high technologies and smart citizens are tools to apply these strategies. Therefore, solutions based on these tools are fundamental solutions towards modern cities.

In this research, $i$-Sustainbility Plus founded on sustainability, innovation and high technologies and U-DSR theory based on sustainability pillars and comprehensive strategic urban factors are introduced as solutions to create modern cities towards making the World a better place for living. These solutions are a kind of invention. Authors found out factors concerned on creating modern models and eventually these two models were designed based on authors' researches. If these models are utilized in reality and are practical, they are turned to innovation. These models are located in the invention level. In addition, Blue-Green city is also a kind of invention in this research. These inventions are created through thought, novel idea, and ideation. 


\section{Discussion}

\subsection{Sustainable and Livable World through Blue-Green Cities}

Low sustainability; wars; sanctions; and challenges made by rapid and unplanned urbanization, especially environmental challenges, risks like natural disasters and accidents, make cities unsustainable with a low quality of life and livability. Therefore, the cities and the world need to be changed to deal with these challenges to preserve the world for future generations and improve quality of life for present. Generally, rapid urbanization and globalization influence every aspect of life in every nation that modern phase of living is required to achieve sustainable globalization. Sustainable globalization could reduce urbanization challenges through economic and financial benefits, technology, movement of talent, geopolitical, and reducing poverty and inequality. There is a relation among globalization, livability and sustainability. Sustainable globalization could create social and sustainable environment and achieve economic growth and high quality of life. Therefore, the new concept of urban living, which can tackle these restrictions in order to create modern and sustainable cities with high quality of livability and life, is required to gain sustainable globalization. These cities could make the world a better place for living.

Green settings, neutral $\mathrm{CO}_{2}$ areas, sustainable water management policies, areas with high quality of life through high standards and facilities, and sustainable urban settings with low global challenges based on Blue-Green strategies, are indicators required to develop modern cities. These features make urban areas that might be able to control global challenges and develop sustainability towards areas with a high quality of livability and life. Generally, modern areas will supply humans' needs ranging from physical health, family, education, employment, wealth, safety, and security to freedom, religious beliefs, environment, and livability. In other words, modern areas are able to supply humans' needs founded on Maslow' Hierarchy towards enhancing citizens' satisfactions of their lives.

Generally, there is a relation among sustainability, quality of life, livability, and eventually livable urban areas. Sustainability is required to supply humans' needs to improve livability and quality of life. In addition, high quality of livability and life could develop sustainability. Therefore, there is a bilateral relation. These parameters could make urban areas more sustainable, livable and able to tackle global challenges. The below Figure 3 presents this relation:

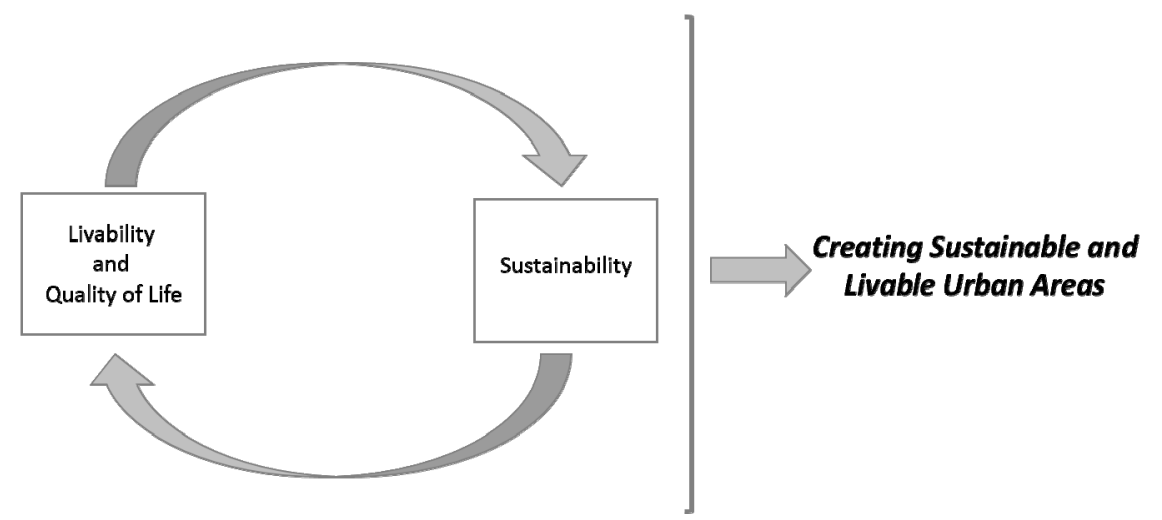

Figure 3. Relation among Modern Urban Areas, Sustainability, Quality of life, and Livability [Authors].

\subsection{Blue-Green Cities}

Blue-Green city is about modern urban areas that are able to make the world a better place for living. Such areas are cities that are aligned with environmentally friendly and sustainable water management. It means that these areas are able to deal with environmental challenges and even other urbanization challenges like health diseases, social responsibility problems, etc.

Modern Blue-Green cities are sustainable livable urban settings founded on two aspects: build an environment that is sustainable and aligned with the natural environment. It is required to apply 
strategies, policies and solutions to make a sustainable environment, even being environmentally friendly. Developing seven suggesting pillars of sustainability including economic sustainability, social sustainability, cultural sustainability, educational sustainability, technical sustainability, political sustainability, and environmental sustainability could achieve the multidimensional aspects of these modern cities.

Environmental sustainability strategies are concerned with reducing humans' activities that disturb nature. They are founded on being environmentally friendly and having effective water management in order to preserve the nature for future generations. Therefore, these strategies are fundamental tools to have in modern cities. Technical and education sustainability are needed to train knowledgeable and expert capitals who are able to implement solutions to create Blue-Green cities. For instance, Industry 4.0 (I4.0) is an intense tool to be utilized in businesses and industries to improve energy management and efficiency; however, only a few countries can manipulate it. So, technical and educational sustainability are vital to keep up with technologies in order to use them in developing sustainability. In addition, cultural sustainability is a tool to make citizens be aware of the importance of modern cities, and to make them concerned with sustainability. Besides all the mentioned indicators, economic and political sustainability are needed to create a situation for a country to develop sustainability. It means that political sustainability is needed for countries to be able to develop other tools like technical sustainability; and economic sustainability is a fundamental means to improve technical, educational and other strategies. Eventually, social sustainability will be required to improve security, safety, wealth, etc., in a city. Therefore, all these sustainability indicators play an important role in creating modern urban areas.

These seven indicators could make modern urban areas have a high quality of life and livability. High quality of resident life without compromising future sustainability would be achieved in Blue-Green cities. In addition, global challenges would be decreased by the potential of such areas based on sustainability to deal with these risks. Fundamentally, this concept of urban area could be used as a path to make the world a better place for living.

Different techniques and tools are required to create Blue-Green cities based on seven pillars of sustainability. The main tools are:

\section{$>$ Comprehensive Strategic Urban Plan:}

B Blue-Green and smart infrastructure

- Project management concerned with Blue-Green strategies and sustainability

$\bigcirc \quad$ Value engineering as an improvement tool

Strategic urban planning could help cities to realize their weaknesses and find out solutions to improve them. Comprehensive strategic urban planning includes all sectors of a country such as businesses, industries, urban development, etc., therefore, it could improve all functions and processes in a country to develop indicators of sustainability. In other words, strategic urban planning helps government and all businesses in a country to improve their performances and be aligned with sustainability strategies. Blue-Green and smart infrastructure, proper project management and value engineering are indicators needed to achieve proper strategic urban planning. Blue-Green and smart infrastructure is required to achieve sustainable urban design in an urban plan towards environmental, economic and social sustainability. Utilizing proper project management is vital in different industries and businesses to gain success, productivity and efficiency through reducing and controlling risks. In addition, value engineering could be used as an improvement tool to gain proper strategies. Fundamentally, comprehensive strategic urban planning based on Blue-Green and smart strategies play significant roles in creating Blue-Green cities.

\section{$>$ Innovation:}

Innovation is a tool to implement solutions towards sustainability. Innovation management, innovation process, financial innovation, and innovative techniques like TRIZ algorithm and IMP ${ }^{3}$ rove 
could be made successful businesses, industries and government towards sustainable comprehensive strategic urban plan. This means that innovation is a means to find out solutions towards sustainable development. Fundamentally, innovation as an innovative path is required to find out, develop and implement sustainability.

\section{Digitalization, Smartness and Technologies such as IT, ICT, IoT, IoE, as techniques towards ubiquitous services:}

The first, second, third, and fourth waves (ages) have passed. Since the 70s, enhancement of the technologies has been the main reason for improving environment, business, economic, and eventually peoples' life. Technology could influence on every aspect and level of businesses such as marketing, productivity, mobility, operations efficiency, security and effective costumer communication; industries like energy management and efficiency being in alignment with the environment; and infrastructure indicators such as mobility, risk management, and strategic urban planning towards obtaining their goals and sustainable development. Therefore, high technologies are tools utilized to cultivate strategies required for sustainability.

The below Figure 4 presents five ages and their features:

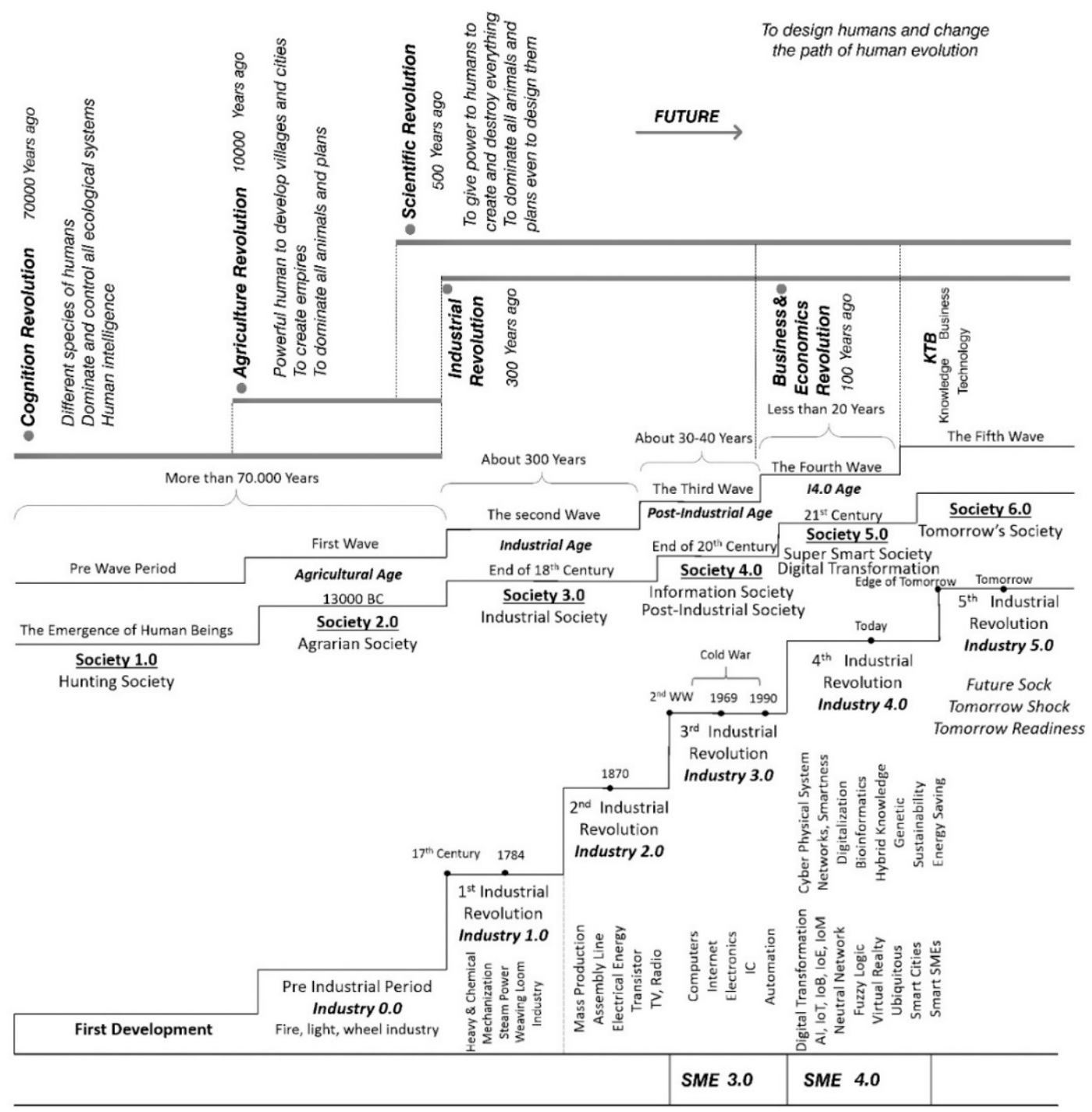

Figure 4. The 5th wave/tomorrow age Theory and Evaluation of Ages (Hamid Doost Mohammadian, [9,41,42]). 
High technologies like digitalization, Information Technology (IT), Information and Communication Technology (ICT), Internet of Thing (IoT), Internet of Business (IoB), Internet of Energy (IoE), and Internet of Manufacturing (IoM) are high technology techniques to implement strategies and solutions needed for sustainable development.

Technology is one of the main tools to create, develop and apply strategies, solutions and techniques such as smart mobility, value engineering, etc., required for Blue-Green cities. High technologies could create strategies and solutions towards sustainable development. Renewable energies, waste as a new source of energy, hybrid cars, agile businesses, E-services, and ubiquitous concepts are all founded on high technology. Therefore, high technology is a fundamental tool for designing Blue-Green cities. In addition, Industry 4.0 and Society 5.0 founded on technology are the other techniques that could be used towards sustainable development through advantages such as: reducing cost, creating a more friendly and effective environment, sustainable energy management, improving mass production related to economic costs, creating job opportunities, and improving efficiency and productivity of businesses towards economic sustainability.

\section{$>$ Ubiquitous services, smart and intelligence businesses and etc.:}

Ubiquitous services are paths to be kept up with rapid and growing demands of citizens, as well as supplying modern needs. Ubiquitous cities are the best solutions for populated urban settings like Seoul. As people are moving to cities to benefit from better quality of life, the populations of cities are growing; so, urban cities confront the challenges of the growing population. Ubiquitous concept is a path to tackle urbanization challenges.

Figure 5 presents that high technologies such as IT, IoT, IoB, IoE, IoM and so on, seven pillars of sustainability, ubiquitous services based on reality, virtual reality, high technology, ICT infrastructure and smartness and eventually proper strategic urban plan could be used as tools and strategies to develop Blue-Green Ubiquitous City. In other words, these are indicators and factors required to design sustainable and modern urban areas like Blue-Green Ubiquitous City.

Besides these factors, people play important roles in designing Blue-Green cities. In particular, smart citizens are required to be able to create, develop, implement, and utilize these indicators towards Blue-Green cities. According to the position of the citizens, they could play different and several roles in applying these indicators to create modern urban areas. People are categorized in different classes:

$>$ Experts including Urban Developer, Manager and Leaders, IT Experts, Sustainability Experts and Innovation Experts

$>$ Government

$>$ Public Citizens

Professional and educated experts who are able to find out innovative solutions, expert capitals who could manipulate high technologies and innovation to find out strategies to achieve sustainability strategies. In addition, smart citizens who are aware of tools required for sustainability and are aligned with sustainability strategies are required. Basically, citizens play important roles in creating Blue-Green cities through reducing their activities that are against the environment, enhancing social responsibility, creating proper cultural norms, etc. Besides experts and public citizens, the government could have a big influence in designing modern cities through its supports and making a situation to develop sustainability. Fundamentally, government plays significant roles in bringing about political, social, cultural, technical, educational, and economic sustainability. In other words, the government is the main factor required to make a proper platform to develop sustainability pillars; however, all citizens are big factors in bringing about environmental sustainability. 


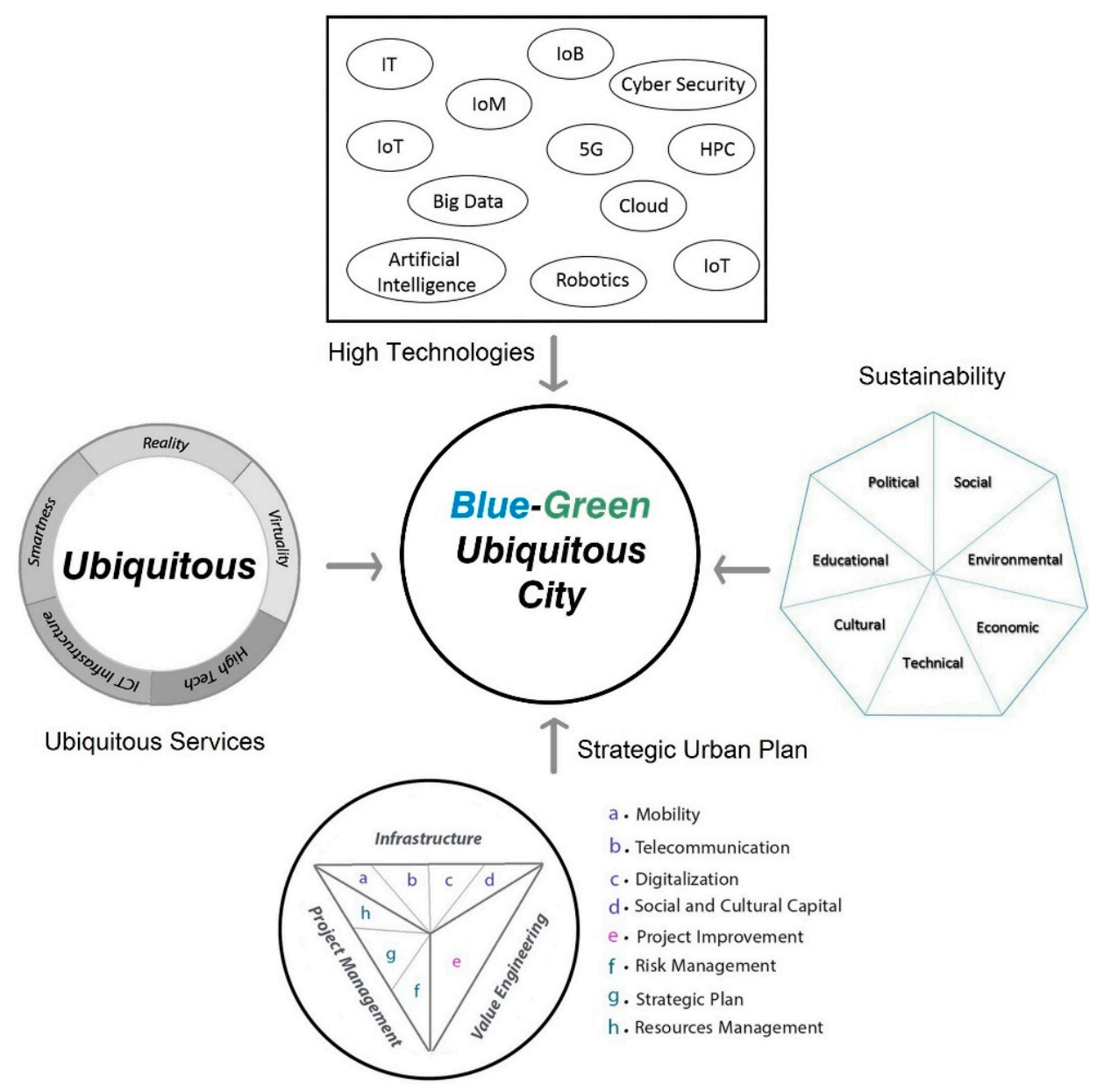

Figure 5. Towards Blue-Green Ubiquitous Cities through Different Tools (Authors).

People play significant roles in creating and applying indicators required to design modern cities and to preserve the World for upcoming generations. In other words, to create sustainable and proper urban areas like Blue-Green cities, smart citizens are required. Citizens as members of the community will influence the future of countries. Blue-Green cities need smart citizens who are intellectual; knowledgeable; aware of the role of new technologies, computing and networks in creating new phase of cities; and are able to apply them in their different aspects of their lives. Smart people are aware of their community, their society, their people, and their needs. They know how they could respond and supply their needs and set them in their plan. Generally, smart citizens think, plan and utilize information technology and ubiquitous technology to supply needs; increase productivity, efficiency and quality; save time and so on. Fundamentally, people as citizens, experts and governments through several roles would play important roles in developing Blue-Green cities.

Blue-Green Cities are based on Blue-Green infrastructure that is a fundamental platform for high quality of life and livability. In other words, Blue-Green infrastructure could develop sustainability as well as a high quality of livability and life.

The below Figure 6 presents privileges of Blue-Green infrastructure: 


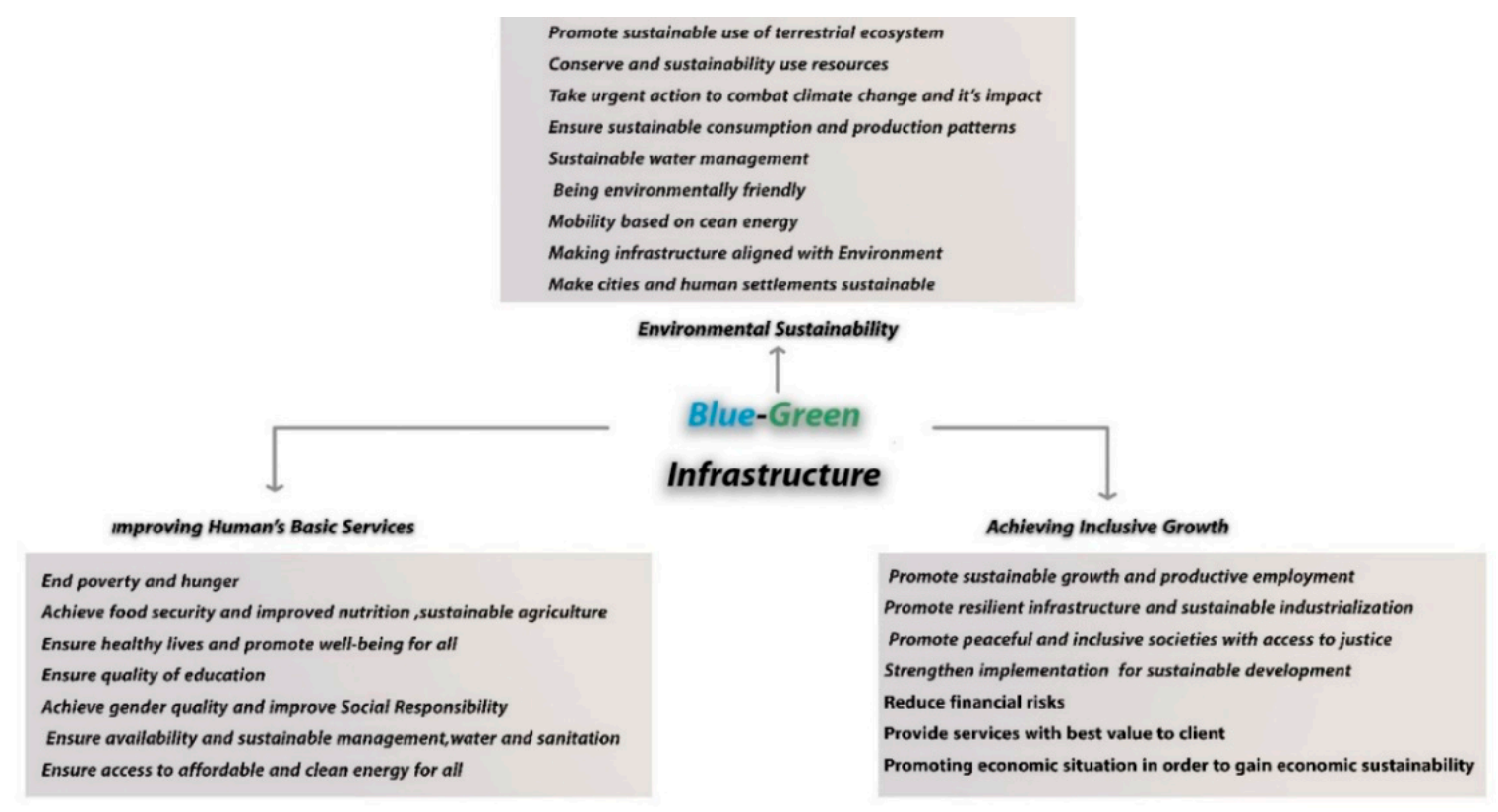

Figure 6. Blue-Green Infrastructure (Authors, [43]).

The main characters of Blue-Green cities are Blue-Green infrastructure, wealth, safety, high quality of health, sustainable education, sustainable economic, sustainable social, sustainable environment, and eventually high quality of life. These features directly and indirectly influence people's behavior and make them more satisfied. In other words, Blue-Green infrastructure would supply humans' needs and bring about a high quality of life, which are features of life satisfaction for citizens. Therefore, such infrastructure is able not only to create Blue-Green cities, but also to make happier citizens. Fundamentally, a better world for living could be achieved through modern Blue-Green areas.

The below Figure 7 presents U-DSR theory which was realized by authors to create modern urban areas with a high quality of livability and life. This theory was introduced in article "An Applied Study of Sustainability Plus, Digitalization, Urban Planning and Environmental Challenges key to Green Ubiquitous Cities and Mobility as a new Concept of Urban Living". Therefore, U-DSR is a path to create Blue-Green Cities towards a sustainable and livable world.

Fundamentally, Blue-Green Ubiquitous cities could create a more sustainable world with high quality of life and high livability. In addition, U-DSR theory could be used as a way towards such urban areas. U-DSR theory shows that sustainability and comprehensive strategic urban plan are two factors required to design modern cities. Ubiquitous life, wealth and sustainability are the main characters of modern cities achieved by sustainability and proper comprehensive strategic urban plan. Furthermore, ubiquitous services are needed to gain modern areas with sustainability, high quality of livability, life, wealth and ubiquitous life.

\section{3. i-Sustainability Plus as a Theory towards Blue-Green Ubiquitous Cities}

As it was mentioned, different tools, strategies, policies, and solutions based on specific indicators such innovation, sustainability and high technologies are required to design Blue-Green ubiquitous cities. 


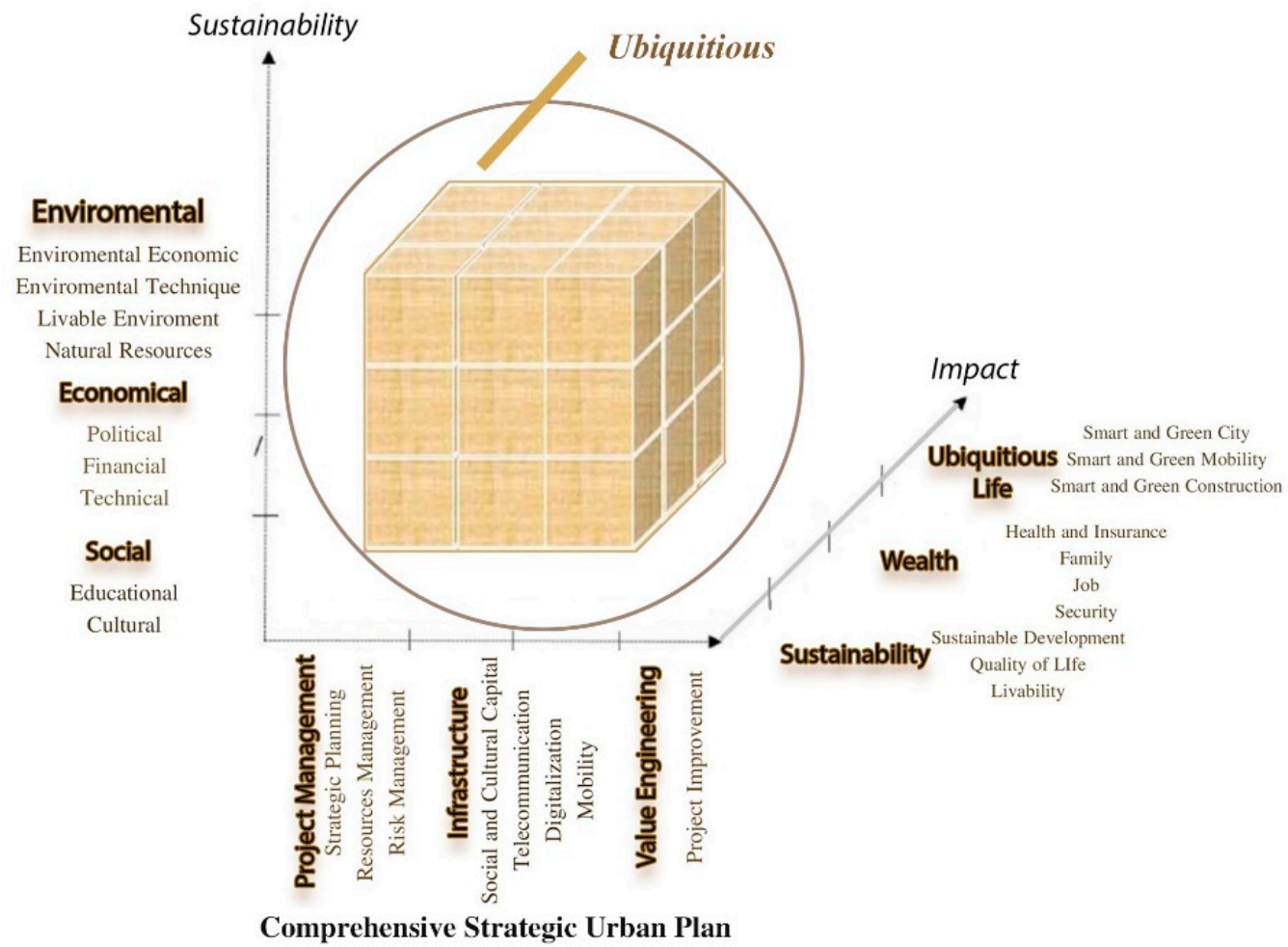

Figure 7. U-DSR Theory (Authors, $[8,28]$ ).

According to two fundamental tools, high technologies and innovation, i-Sustainability Plus theory was introduced by authors as a path to achieve Blue-Green Strategies. This theory is based on seven pillars of sustainability, Ubiquitous concept and Innovation.

In this theory, innovative management is about innovation in business, marketing and technology systems to gain successfulness and the best result. Innovation has an important role in not only the business innovation model and marketing innovation, but also in whole processes of an organization. Accordingly, technology innovation is realized as a separate segment of innovative management in sustainability plus theory. Technological innovation is related to creating new ideas based on technology or utilizing knowledge to find out innovative and new solutions to improve processes and situations of organization. In particular, new technologies such as digitalization, IT, ICT, etc., influence innovative processes. The most important advantages of new technology are:

- Accelerating innovative processes

- Realizing new chances in markets

- Creating new ideas and using them into innovations

- Modeling products and services into market to test them in order to find out new results

- Developing businesses with maximum profit and effectiveness

In addition, high sustainability that includes environmental sustainability, economic sustainability, social sustainability, cultural sustainability, educational sustainability, technical sustainability, and political sustainability is required to achieve sustainability plus theory. Further, innovation is a tool to find paths to gain high sustainability.

Fundamentally high technologies, digitalization and ubiquitous would play roles in achieving this theory. Digitalization and ubiquitous concepts could be used as tools to improve high sustainability and innovative management. Therefore, in this theory, authors use digitalization and ubiquitous concept as one of the main pillars. 
i-Sustainability plus is the integration of high sustainability, innovative management and digitalization in order to gain the best results, effectiveness and profits. The below Figure 8 present this theory:
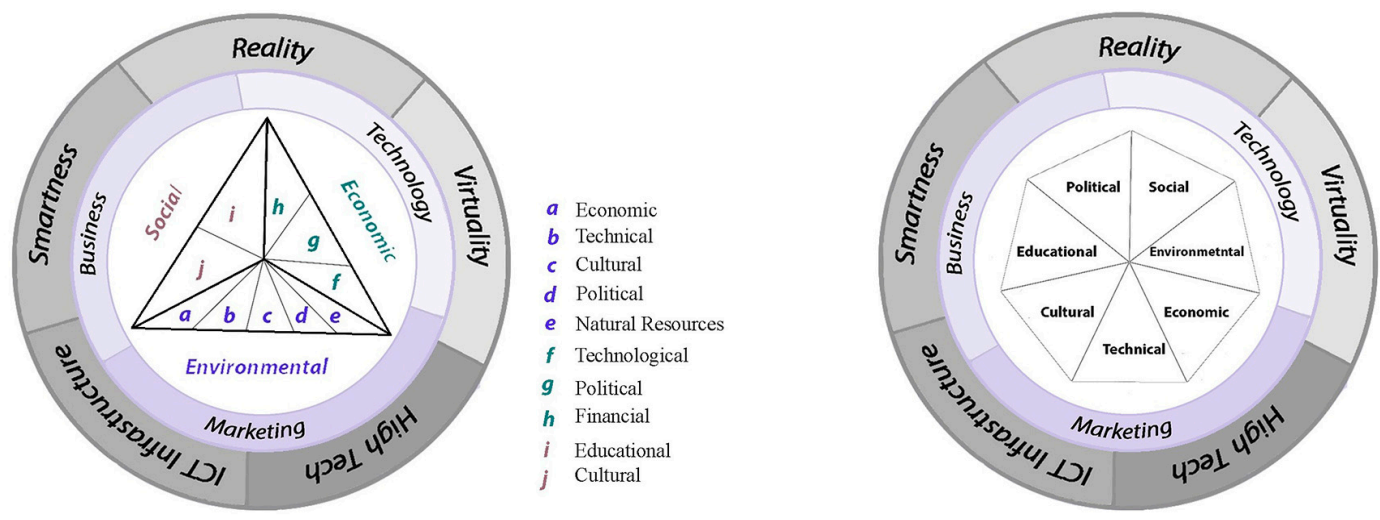

Figure 8. i-Sustainability Plus Theory (Prof. Dr. Hamid Doost Mohammadian, [8,21,44,45]).

Different innovative tools such as TRIZ Algorithm, IMP ${ }^{3}$ rove, Doblin innovation models, and innovative management could be utilized as sub-tools towards i-Sustainability Plus theory. In particular, innovation is not only a component of i-Sustainability Plus but is also a technique to achieve this theory. So, innovation has important roles in designing innovative theories, innovative strategies and innovative path towards these theories to gain sustainable and livable urban settings.

As it was mentioned, i-sustainability Plus theory could be used to create Blue-Green and Ubiquitous areas with a high quality of life.

In modern sustainable and livable urban settings, high facilities like high quality of education, employment, entertainment, housing, and wealth made humans' needs be supplied; so, sustainability and high quality of livability could be gained. Generally, i-Sustainability plus could influence achieving U-DSR theory, even it plays an important role in creating sustainable and livable urban areas concerned with other theories. In particular, i-Sustainability Plus is a path to design modern sustainable urban settings with high quality of life. In other words, i-Sustainability Plus theory is an innovative tool to find out solutions of Blue-Green strategies in order to create Blue-Green Ubiquitous urban areas needed for a better world. Such urban areas will create a sustainable world through struggling with global challenges, developing sustainability, supplying humans' needs, and improving livability and quality of life.

Blue-Green Ubiquitous areas bring about wealth, ubiquitous life, sustainable development, modern facilities to supply humans' needs, and high standards of living. To conclude, modern sustainable and livable urban areas like Blue-Green Ubiquitous cities is the best solution to make the World a better place for living through reducing global challenges and gaining sustainable development. Generally, innovation; innovative management; high technologies such as IT, ICT, IoT, IoB, IoE, and digitalization; sustainability; and proper comprehensive strategic urban plans are the main tools to create new modern urban settings. [1,45-59].

The below Figure 9 presents how U-DSR theory and the other innovative algorithms and tools help us towards more sustainable and livable world for living: 


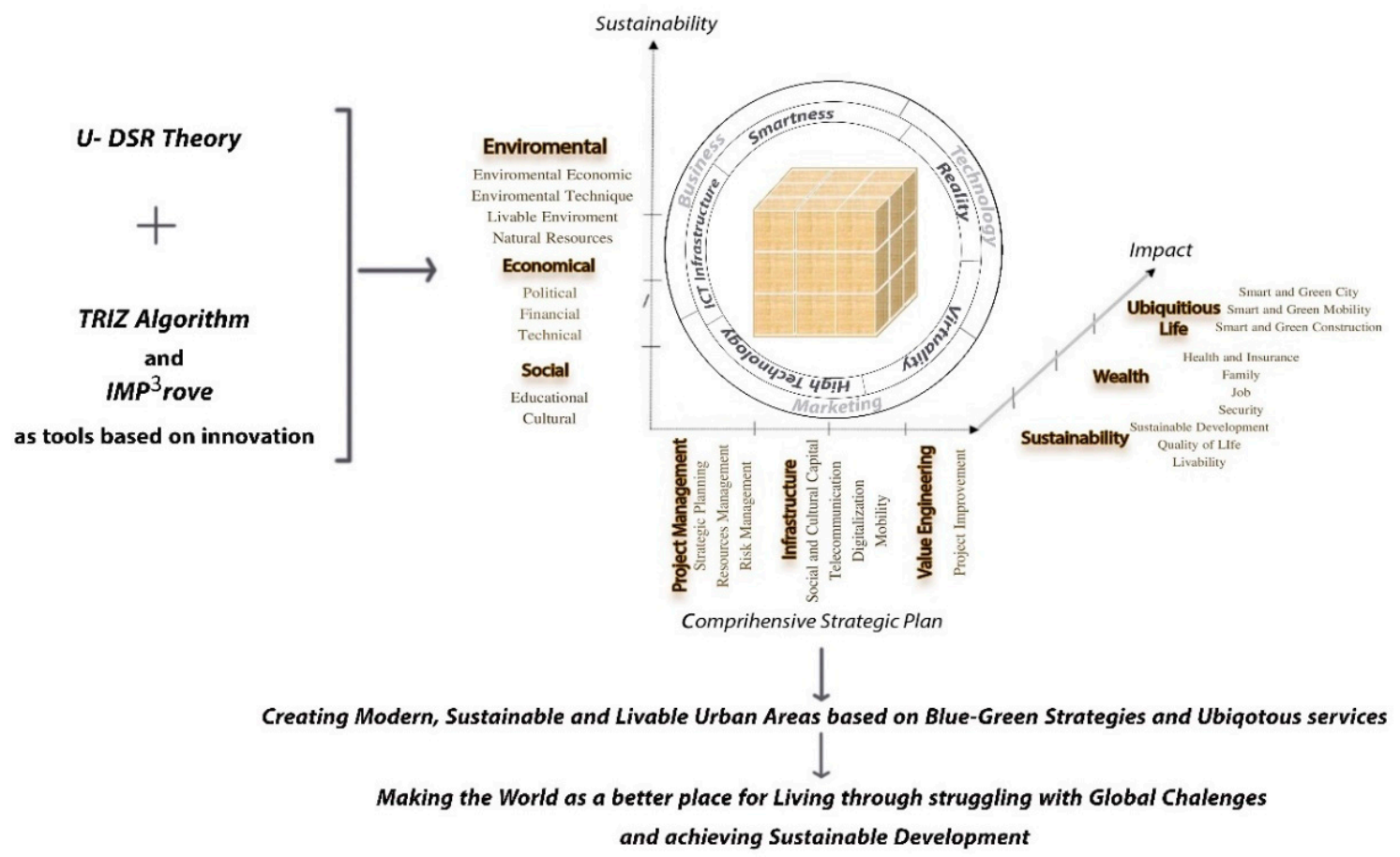

Figure 9. Towards more Sustainable and Livable World for Living (Authors).

Fundamentally, modern and sustainable concept for urban areas are needed to make the world as a better place for living. Different tools, strategies and policies such as U-DSR theory introducing by authors, TRIZ and other innovation algorithms and tools, sustainability and so on could play role in developing modern and sustainable urban areas towards better world with high life quality, livability and sustainability.

In particular, to achieve U-DSR theory, all categories of people (experts, public citizens and government) play significant roles. Fundamentally, people could influence creating modern Blue-Green cities through different techniques and tools.

Discussion was based on research and analyses of articles [1,7-10,12,13,21,28-37,41-51,53-59].

\section{Conclusions}

Global problems threaten the planet through destroying the environment, natural resources and human' being by worsening the quality of livability and life. Fundamentally, these challenges eliminate humanities and the planet. So, it is vital to deal with these challenges. Sustainable development is a proper solution. Therefore, techniques and tools to achieve sustainable development are required.

Sustainable development could struggle with risks to threaten the future of the world and humanities, supply humans' needs in the most sufficient path, and create sustainable and livable areas with a high quality of life. Although green and environmentally friendly strategies are needed to gain sustainable development, it is not sufficient. Many challenges are concerned with water management such as water shortage, water pollution, etc. So, Blue strategies are required, excluding green and environmentally friendly policies. Generally, Blue-Green strategies are vital to achieve sustainable development in cities. Therefore, creating modern urban areas based on Green-Blue and sustainability strategies is a path towards sustainable development. In addition, rapid and unplanned urbanization has an important role in making global challenges worsen. So, techniques are required to make Blue-Green cities keep up with growing demands. To gain it, ubiquitous services and life are recommended as an innovative solution. U-services such as U-banking, U-education, U-home, U-shopping, U-healthcare, U-business, U-government, U-mobility, smart and intelligent building, U-port, etc., make U-cities and U-life. U-services and U-life could improve quality of life through producing new jobs, increasing citizens' knowledge, and promoting security, as well as having 
other advantages. In particular, U-services and U-life are tools to proceed Blue-Green strategies. Fundamentally, Blue-Green Ubiquitous cities could be a solution to achieve sustainable development. These modern sustainable settings with high livability and quality of life are the best solution to struggle with urbanization challenges in order to maintain the world and humanities. Quality of life and livability are the most important parameters concerned with human life.

According to this research, it is concludes that:

1. Global challenges threaten not only the maintenance of the world, but also humanities. So, it is vital to struggle with these problems.

2. Creating modern livable settings with low risks of global challenges and high sustainability is a solution to struggle with global challenges in order to gain sustainable development, maintain the environment and planet for future generations, and improve quality of life in cities.

3. Blue-Green urban settings concerned with green strategies, sustainable water management and being environmentally friendly are required to develop modern livable areas.

4. In addition, sustainable urban areas are not sufficient. Besides sustainability, smartness is required to make urban settings keep up with growing humans' needs.

5. Ubiquitous cities are required to make areas aligned with supplying rapid urbanization needs.

6. Fundamentally, the Blue-Green ubiquitous urban setting is the path towards sustainable development, maintaining the world, and making it a better place for living.

7. To achieve Blue-Green ubiquitous settings, U-DSR theory is recommanded by the authors. Sustainability and Comprehensive Strategic Urban Planning concerned with Blue-Green policies and ubiquitous services are needed to achieve this theory.

8. The U-DSR model could make modern livable urban areas with high sustainablity, wealth, ubiquitous life, high livability, and quality of life.

9. In particular, techniques and tools are required to gain indicators needed for U-DSR theory. Based on the authors' point of view, i-Sustaianability Plus is an innovative techniques to develop U-DSR theory.

10. Innovation has important roles not only in realizing solutions towards i-Sustainability Plus theory and U-DSR model, but also in creating another innovative theory towards sustainable and livable urban areas.

11. Blue-Green Ubiquitous cities could be designed through innovation, sustainability, environmental friendliness in order to plan sustainable and smart cities, smart citizens and governments.

12. Modern livable urban settings could be achieved through Blue-Green strategies; smartness; digitalization; high technologies such as IT, IoT, and IoE; and innovative solutions.

Fundamentally, in this research, Blue-Green Ubiquitous city is realized as a key to deal with global challenges to achieve sustainable development and make the world a better place for living through improving livability and quality of life. People would play important and different roles based on their position in creating such areas. The role of humans in achieving sustainable development and designing Blue-Green cities could be a topic for future research.

Author Contributions: Investigation, H.D.M.; F.R.; supervision, H.D.M.; visualization, H.D.M. and F.R.; writing-original draft, H.D.M. and F.R. All authors have read and agreed to the published version of the manuscript.

Funding: This research received no external funding.

Conflicts of Interest: The authors declare no conflict of interest.

\section{References}

1. Nazeer, M.; Tabassum, U.; Almas, S. Environmental Pollution and Sustainable Development in Developing Countries. Pak. Dev. Rev. 2016, 55, 589-604. [CrossRef] 
2. Feil, A.; Schreiber, D. Sustainability and sustainable development: Unraveling overlays and scope of their meanings. Cad. EBAPE. BR 2017, 14, 667-681. [CrossRef]

3. United Nations. Our Common Future, Brundtland Report; Chapter 2: Towards sustainable development; United Nation World Commission on Environment and Development; United Nations: Oslo, Norway, 1987.

4. Barbier, B.; Burgess, E.C.J. The Sustainable Development Goals and the systems approach to sustainability. Economics 2017, 11, 1-23. [CrossRef]

5. Basiago, A.D. Economic, social, and environmental sustainability in development theory and urban planning practice. Environmentalist 1998, 19, 145-161. [CrossRef]

6. Greenwood, L.; Rosenbeck, J.; Scott, J. The Role of the Environmental Manager in Advancing Environmental Sustainability and Social Responsibility in the Organization. J. Environ. Sustain. 2012, 2, 5. [CrossRef]

7. Doost Mohammadian, H.; Rezaie, F. An applied comparative study about the countries with low sustainability and high $\mathrm{CO}_{2}$-emission and advanced sustainability knowledge in Europe and giving practical models to improve and implement sustainability solutions (case study: Germany and Iran). In Proceedings of the 6th International Conference on Civil, Architectural and Environmental Sciences, Stockholm, Sweden, 19 June 2019.

8. Doost Mohammadian, H.; Rezaie, F. Sustainable Innovative Project Management: Response to Improve Livability and Quality of Life, CaSE Studies. Inventions 2019, 4, 59. [CrossRef]

9. Doost Mohammadian, H.; Rezaie, F. The role of IoE-Education in the 5th wave theory readiness \& its effect on SME 4.0 HR competencies. In Proceedings of the 2020 IEEE Global Engineering Education Conference (EDUCON), Porto, Portugal, 27-30 April 2020.

10. Blue-Green Cities: Demonstrating the Multiple Benefits to Blue-Green Infrastructure. Newcastle University. Available online: www.bluegreencities.ac.uk (accessed on 30 March 2020).

11. Department of Environment, Land, Water and Planning. Planning a Green-Blue City. Produced with Assistance from E2Designlab; Department of Environment, Land, Water and Planning: East Melbourne, Australia, 2017.

12. Gehrels, H.; Meulen, S.; Schasfoort, F. Designing Green and Blue Infrastructure to Support Healthy Urban Living; TO2 Federatie: Utrecht, the Netherlands, 2016.

13. Ghofrani, Z.; Sposito, V.; Faggian, R. A Comprehensive Review of Blue-Green Infrastructure. Int. J. Environ. Sustain. 2017, 6. [CrossRef]

14. Sovacool, B.K. Energy policymaking in Denmark: Implications for global energy security and sustainability. Energy Policy 2013, 61, 829-839. [CrossRef]

15. Seele, P.; Lock, I. The game-changing potential of digitalization for sustainability: Possibilities, Perils, and Pathways. Sustain. Sci. J. 2017, 12, 183-185. [CrossRef]

16. D'Auria, A.; Bifulco, F.; Tregua, M. Digital City towards Smart City: A theoretical overview. In Proceedings of the 2nd Year of International virtual Scientific Conference, University of Zilina, Zilina, Slovakia, 9-13 June 2014.

17. Cocchia, A. Smart and Digital City: A Systematic Literature Review; Springer International Publishing: Cham, Switzerland, 2014.

18. Trindade, E.P.; Hinnig, M.P.F.; Da Costa, E.M.; Marques, J.S.; Bastos, R.C.; Yigitcanlar, T. Sustainable development of smart cities: A systematic review of the literature. J. Open Innov. Technol. Mark. Complex. 2017, 3, 11-14. [CrossRef]

19. Sarma, A. Smart City and Urban Sustainability; Tech Vol cum Souveni; Institution of Engineers: Kolkata, India, 2016.

20. Sung, H.J. Smart Cities Seoul: Case Study; ITU-T Technology Watch Report; ITU: Geneva, Switzerland, 2013.

21. Doost Mohammadian, H.; Rezaie, F. Blue-Green Ubiquitous Cities: A Response to Create Sustainable and Low Emissions Greenhouse Gases Urban Areas with High Liveability and Quality of Life. Proceeding of the 2nd International Conference on Advanced Research in Humanities and Art, Venice, Italy, 21 May 2019.

22. Hernandez, M. Basic concept of innovation and innovation management. In Head of Technology and Innovation; Ericson Espana: Barcelona, Spain, 2010.

23. Tohidi, H.; Jabbari, M.M. Different Stages of Innovation Process. Procedia Technol. 2012, 1, 574-578. [CrossRef]

24. Sengupta, J. Theory of Innovation: A New Paradigm of Growth; Springer: Berlin/Heidelberg, Germany, 2014.

25. Kylliäinen, J. Key Innovation Management Models and Theories. 2018. Available online: https://www.viima. com (accessed on 6 September 2018). 
26. Clayton, C. The Innovators Dilemma: When New Technologies Cause Great Firms to Fail; Harvard Business School: Boston, MA, USA, 1997.

27. Paradis, Z.; Mc Gaw, D. Naked Innovation-Uncovering a Shared Approach for Creating. Master's Thesis, IIT Institute of Design, Chicago, IL, USA, 2007.

28. Doost Mohammadian, H.; Rezaie, F. An Applied Study of Sustainability Plus, Digitalization, Urban Planning and Environmental Challenges- key to Green Ubiquitous Cities and Mobility as a new Concept of Urban Living (case studies: Songdo and Seoul in South Korea). In Proceedings of the 6th International Conference on Civil, Architecture and Environmental Sciences, Stockholm, Sweden, 19 June 2019.

29. Yeon Mee, K.; Hyun Soo, K.; Soo Young, M.; So-yeon, B. Ubiquitous Eco-City Planning in Korea; A Project for the Realization of Ecological City Planning and Ubiquitous Network Society; Real Corp 2009: Cities 3.0—smart, sustainable, integrative; The Korea Science and Technology Svience: Seoul, Korea, 2009.

30. Anderson, R. Alleviating World Suffering: The Challenge of Negative Quality of Life; Springer: Cham, Switzerland, 2017.

31. Benevolo, C.; Dameri, R.; D'Auria, B. Smart Mobility in Smart City: Action Taxonomy, ICT Intensity and Public Benefits; Springer International Publishing: Cham, Switzerland, 2016.

32. Finnveden, G.; Gunnarsson-Ostling, U. Sustainable development goals for cities. In Proceedings of the JPI Urban Europe Symposium “Shaping Common Ground in Urban Sustainability”, Brussel, Belgium, 27 October 2016.

33. Giap, T.; Thye, W.; Grace, A. A new approach to measuring the livability of cities: The Global Livable Cities Index. World Rev. Sci. Technol. Sust. Dev. 2014, 11, 176-196. [CrossRef]

34. Maksimovic, C.; Mijic, A.; Smith, K.M.; Suter, I. Blue-Green Solutions. A systems Approach to Sustainable, Resilient and Cost-Efficient Urban Development; Climate-KIC: London, UK, 2017.

35. Mella, P.; Gazzola, P. Sustainability and Quality of Life: The Development Model; Faculty of Business and Economics: Prague, Czeck Republic, 2015.

36. HerRman, T.; Lewis, R. What Is Livability? SCI Research Director; University of Oregon: Eugene, OR, USA, 2017.

37. Al-Thani, S.; Amato, A.; Koc, M.; Al-Ghamdi, S. Urban Sustainability and Livability an Analysis of Doha's Urban-form and Possible Mitigation Strategies. Sustainability 2019, 11, 786. [CrossRef]

38. Cardone, P.; Cote, M.; Gustafson, H.; Kearney, P.; Worthy, J. The Implications of Globalization on the Sustainability of Society; Worcester Polytechnic Institute: Worcester, MA, USA, 2010.

39. OECD. Perspectives on Global Development 2019: Rethinking Development Strategies; OECD: Paris, France, 2018.

40. Rees, W. Globalization and Sustainability: Conflict or Convergence? Bull. Sci. Technol. Soc. 2002, 22, $249-268$. [CrossRef]

41. Doost Mohammadian, H. IoT-Education technologies as solutions towards SMEs' educational challenges and I4.0 readiness. In Proceedings of the 2020 IEEE Global Engineering Education Conference (EDUCON), Porto, Portugal, 27-30 April 2020.

42. Doost Mohammadian, H.; Doost, F.; Assante, D. IoT-education policies on national and international level regarding best practices in German SMEs. In Proceedings of the 2020 IEEE Global Engineering Education Conference (EDUCON), Porto, Portugal, 27-30 April 2020.

43. Available online: www.un.org (accessed on 22 April 2018).

44. Doost Mohammadian, H.; Rezaie, F. Giving three Practical Innovative Models based on IMP3rove and TRIZ in Smart and Sustainable Mobility: Keys towards Blue-Green, Sustainable and Livable Urban Area (Case studies: Denmark, South Korea). In Proceedings of the International Congress on Engineering, Technology and Innovation, Darmstadt, Germany, 1-2 August 2019.

45. Available online: https://www.mdpi.com/journal/asi/special_issues/hybrid_smes (accessed on 30 March 2020).

46. Ruen, K. The Quality of Life and the Environment. In Proceedings of the Asia Pacific International Conference on Environment-Behavior Studies, Famagusta, North Cyprus, 7-9 December 2011.

47. Shamsuddin, S.; Abu Hassanb, N.; Bilyaminb, S. Walkable Environment in Increasing the Livability of a City. In Proceedings of the ASEAN Conference on Environment-Behavior Studies, Bangkok, Thailand, 16-18 July 2012.

48. Maslow, A.H. A Theory of Human Motivation. Psychol. Rev. 1943, 50, 370-396. [CrossRef]

49. Nwankwoala, H.N.L. Causes of Climate and Environmental Changes: The need for Environmental-Friendly Education Policy in Nigeria. J. Educ. Prac. 2015, 6, 224-234. 
50. Negev, M.; Garb, Y.; Biller, R.; Sagy, G.; Tal, A. Environmental Problems, Causes, and Solutions: An Open Question. J. Environ. Educ. 2010, 41, 101-115. [CrossRef]

51. Guthridge-Gould, S.; Doorman, E.; Hesselink, F. Environment and Security: Challenges for Change: Report on the Roundtable Workshop on Environment and Security. In Proceedings of the IUCN World Conservation Congress, Barcelona, Spain, 6 October 2008.

52. Bughin, J.; Manyika, J.; Woetzel, J. Smart Cities: Digital Solutions for a More Livable Future; McKinsey Global Institute: Belgium, WI, USA; Shanghai, China, June 2018.

53. Energy Management: A Comprehensive Guide to Controlling Energy Use; Carbontrust: London, UK, 2011. Available online: https://www.carbontrust.com/media (accessed on 30 March 2019).

54. Braulio-Gonzalo, M.; Bovea, M.D.; Ruá, M.J. Sustainability on the urban scale: Proposal of a structure of indicators for the Spanish context. Environ. Impact Assess. Rev. 2015, 53, 16-30. [CrossRef]

55. Lehmann, S. Chapter 18 Sustainability on the Urban Scale: Green Urbanism-New Models for Urban Growth and Neighborhoods. In Urban Energy Transition; Elsevier: Amsterdam, The Netherlands, 2008.

56. Doost Mohammadian, H. IoT—a Solution for Educational Management Challenges. In Proceedings of the 2019 IEEE Global Engineering Education Conference (EDUCON), Dubai, UAE, 8-11 April 2019.

57. Available online: www.cisl.cam.ac.uk (accessed on 30 March 2020).

58. Available online: www.improve-innovation.eu (accessed on 30 March 2020).

59. Available online: https://www.mdpi.com/journal/JOItmC/special_issues/Innovation_under_Restrictions (accessed on 30 March 2020).

(C) 2020 by the authors. Licensee MDPI, Basel, Switzerland. This article is an open access article distributed under the terms and conditions of the Creative Commons Attribution (CC BY) license (http://creativecommons.org/licenses/by/4.0/). 